\title{
Transient electrocardiographic abnormalities following blunt chest trauma in a child
}

\author{
Floris E. A. Udink ten Cate • Marc van Heerde • \\ Lukas A. Rammeloo • Jaroslav Hruda
}

Received: 20 October 2007 / Accepted: 19 December 2007 / Published online: 17 January 2008

(C) The Author(s) 2008

\begin{abstract}
Blunt cardiac injury may occur in patients after suffering nonpenetrating trauma of the chest. It encompasses a wide spectrum of cardiac injury with varied severity and clinical presentation. Electrocardiographic abnormalities are frequently encountered. This article presents a case of a child who presented with complete right bundle branch block on the initial ECG at the emergency department. She suffered blunt chest trauma during a horseback riding accident. She was admitted for cardiac monitoring. The electrocardiographic abnormalities resolved within 12 hours. No signs of myocardial injury were found on repeat serum troponin measurement and echocardiography. The natural history of ECG abnormalities in the pediatric age group following blunt chest trauma is limited. Although a complete right bundle branch block may be transient in adult patients, this has not been previously reported in a children. Significant ECG abnormalities can be encountered in children following blunt chest trauma. Although a complete RBBB can be associated with severe injury to the RV, it can also occur with minor injury.
\end{abstract}

Keywords Cardiac contusion - Electrocardiography · Blunt chest trauma $\cdot$ Blunt cardiac injury

F. E. A. Udink ten Cate $\cdot$ M. van Heerde Department of Pediatric Intensive Care, VU University Medical Center, Amsterdam, The Netherlands

L. A. Rammeloo · J. Hruda $(\bowtie)$

Department of Pediatric Cardiology,

VU University Medical Center,

P.O. Box 7057, 1007 MB Amsterdam, The Netherlands

e-mail: J.Hruda@vumc.nl

\author{
Abbreviations \\ BCI Blunt cardiac injury \\ CK Creatine kinase \\ CK-MB Creatine kinase, myocardial isoform \\ ECG Electrocardiography \\ LV Left ventricle \\ RBBB Right bundle branch block \\ RV Right ventricle
}

\section{Introduction}

Blunt cardiac injury (BCI) may occur in patients after suffering nonpenetrating trauma of the chest and should be suspected in all multi-trauma patients presenting to the emergency department $[1,11]$. BCI, or cardiac contusion, is a diagnostic challenge because of nonspecific symptoms and lack of an ideal diagnostic tool. BCI encompasses a wide spectrum of cardiac injury with varied severity and clinical presentation [10-12]. Recognition of BCI is crucial, as it may cause life-threatening arrhythmias or heart failure $[11,12]$. The reported incidence of BCI following blunt chest trauma in adult patients is $3-56 \%$, depending on the diagnostic methods used and the physicians' awareness at admission to a hospital [11].

ECG abnormalities frequently occur in adult patients following trauma to the chest $[3,6,9,11]$. We describe a case of isolated sternal fracture and transient electrocardiographic abnormalities in a child following blunt chest trauma due to a horseback riding accident.

\section{Case report}

A previous healthy 12-year-old girl suffered from blunt chest trauma during a horse riding accident. She fell with 
her chest against a steel fence. On admission at the emergency department she complained of substernal discomfort. Vital parameters were normal. The chest X-ray showed a distal sternal fracture, without retrosternal hematoma. Her ECG showed sinus rhythm with abnormal left-axis deviation of -20 degrees, a complete right bundlebranch block pattern with QRS duration of $132 \mathrm{~ms}$, and STelevation in leads II, aVF, and V3 through V6 (Fig. 1). Echocardiography demonstrated normal ventricular function without direct evidence of intracardiac or vascular injury. Troponin assays were normal at presentation, as well as at 6 and 12 hours after the trauma. She was admitted to the pediatric intensive care unit for cardiac monitoring. Her clinical course was unremarkable without developing arrhythmias or cardiovascular complications. Twelve hours after admission her electrocardiographic abnormalities completely resolved. ECG as well as echocardiographic findings remained normal at 3 months follow-up.

\section{Discussion}

$\mathrm{BCI}$ frequently occurs in nonpenetrating chest trauma and its manifestations include a wide spectrum of cardiac complications [1, 6, 7, 9, 10-12]. Most patients have mild or moderate BCI. Potential life-threatening cardiac complications are uncommon but patients at risk should be recognized early in the course of disease $[6,11]$. Estimates of the prevalence of $\mathrm{BCI}$ in children with chest trauma range from $0-43 \%[4,8]$. Most pediatric $\mathrm{BCI}$ is diagnosed in the context of severe multiple system trauma following road traffic accidents, typically involving an automobile versus a pedestrian $[4,8]$.

Recent studies have investigated the use of various diagnostic tests in trauma patients to accurately diagnose $\mathrm{BCI}$ and to predict the development of cardiac complica- tions [6, 9, 11]. Diagnosing cardiac contusion remains difficult, because most diagnostic tests are nonspecific and no gold standard is currently available $[1,11,12]$. Therefore, a high index of suspicion and clear clinical judgment are equally necessary in the diagnosis and management of patients with $\mathrm{BCI}[2,5,11]$.

An ECG can be used as a screening tool for cardiac injury when the patient is presented at the emergency department and BCI is suspected [1-6]. ECG abnormalities are frequently demonstrated in patients following blunt chest trauma and can be nonspecific [1, 6, 9, 10-12]. Some of the ECG abnormalities can be mediated by noncardiac factors such as hypoxia, anemia, serum electrolyte disturbances, or changes in vagal or sympathetic tone, particularly in multi-trauma patients [11]. Differentiation from cardiac causes is mandatory and requires prompt therapy.

Patients with abnormal ECG findings and suspected BCI should be admitted and monitored, as they are at risk for developing complications. In general, it is suggested that monitoring of cardiac rhythm should be continued for up to 72 hours because of the potential to develop arrhythmias or heart failure [11]. However, there is no consensus in the literature on how to manage pediatric patients with suspected BCI and prospective clinical data on this subject are limited $[4,8]$.

Although a rsr' pattern ("right bundle branch block") in right precordial leads may be normal in children, its combination with an abnormal frontal axis ("bifascicular block") is always abnormal and suggests injury to the right ventricle (RV). In the normal heart, there are differences between the anatomy of the right and the left branches of the His bundle. There is only one main right bundle branch. The left bundle branch divides into an anterior fascicle and a posterior fascicle. A bifascicular block occurs when both the right and the left anterior fascicle are blocked. The ECG
Fig. 1 Initial 12-lead ECG at the emergency department, showing sinus rhythm, heart rate of 91 beats per minute, left axis deviation, complete RBBB, and ST-elevation in leads II, avF, and $\mathrm{V} 3-\mathrm{V} 6$

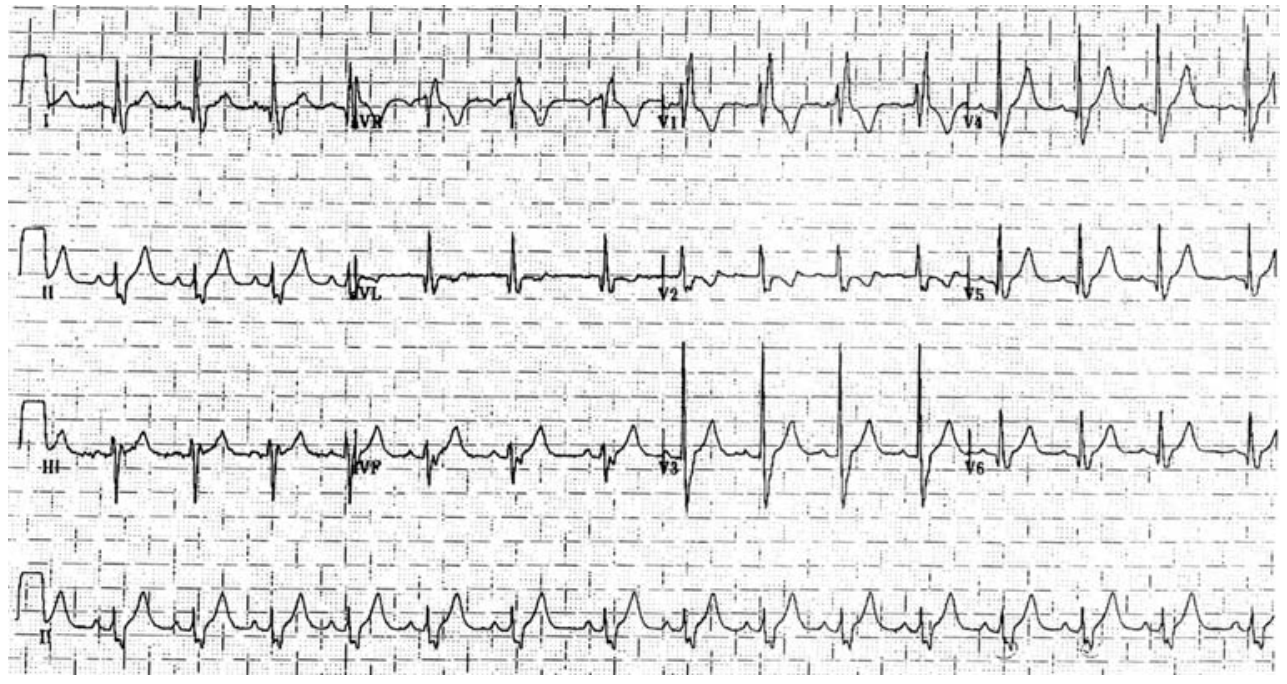


shows complete RBBB with left axis deviation. These ECG changes are indicative of widespread damage to the conducting system [11]. The ECG abnormalities in our patient resolved within 12 hours. We hypothesize that the quantity of damaged myocardial cells was not sufficient to increase the circulating levels of troponin $\mathrm{T}$ above the clinical detection threshold, or cause echocardiographic features of cardiac injury. This hypothesis is supported by three facts: (1) the myocardial wall architecture of the RV is thinner than the left ventricle (LV) [5, 11], (2) several studies have shown that the RV is more frequently injured than the LV in patients with BCI following blunt chest trauma because of the anterior position of the RV in the thorax and its proximity to the sternum $[5,10,11]$, and (3) the impact of the blow to the chest did not cause overwhelming cardiac injury, although a sternal fracture was present.

The natural history of ECG abnormalities in the pediatric-age group following blunt chest trauma is limited $[4,8]$. In adult patients, intraventricular conduction disorders, with RBBB occurring most commonly, usually resolve within several days, but may take as long as 20 days to reverse [1, 3, 9]. Most adult patients reported with conduction disorders following blunt chest trauma had moderate to severe BCI. The clinical course of our patient was unremarkable. Although this report describes only one child, it is suggested that transient complete RBBB may be associated with minor pathologic findings, such as oedema of the conducting tissue [3].

Open Access This article is distributed under the terms of the Creative Commons Attribution Noncommercial License which permits any noncommercial use, distribution, and reproduction in any medium, provided the original author(s) and source are credited.

\section{References}

1. Benitez RM, Gold MR (1999) Immediate and persistent complete heart block following a horse kick. Pacing Clin Electrophysiol 22:816-818

2. Bertinchant JP, Polge A, Mohty D, Nguyen-Ngoc-Lam R, Estorc J, Cohendy R, Joubert P, Poupard P, Fabbro-Peray P, Monpeyroux F, Poirey S, Ledermann B, Raczka F, Brunet J, Nigond J, de la Coussaye JE (2000) Evaluation of incidence, clinical significance, and prognostic value of circulating cardiac troponin $\mathrm{I}$ and $\mathrm{T}$ elevation in hemodynamically stable patients with suspected myocardial contusion after blunt chest trauma. J Trauma 48:924 931

3. Carr KW, Johnspn AD, Gregoratos G (1982) Transient bifascular block following blunt chest trauma. West J Med 137:245-249

4. Dowd MD, Krug S (1996) Pediatric blunt cardiac injury: epidemiology, clinical features, and diagnosis. J Trauma 40:61-67

5. Ferjani M, Droc G, Dreux S, Arthaud M, Goarin JP, Riou B, Coriat P (1997) Circulating cardiac troponin $\mathrm{T}$ in myocardial contusion. Chest 111:427-433

6. Helling TS, Duke P, Beggs CW, Crouse LJ (1989) A prospective evaluation of 68 patients suffering blunt chest trauma for evidence of cardiac injury. J Trauma 29:961-966

7. Hosaka Y, Kodama M, Chinushi M, Washizuka T, Sugiura H, Satou K, Aizawa Y (2004) Intramyocardial hemorrhage caused by myocardial contusion. Circulation 109:277

8. Ilstad ST, Tollerud DJ, Weiss RG, Cox JA, Martin LW (1990) Cardiac contusion in pediatric patients with blunt thoracic trauma. J Pediatr Surg 25:287-289

9. Kettunen P (1984) Cardiac damage after blunt chest trauma, diagnosed using CK-MB enzyme and electrocardiogram. Int $\mathrm{J}$ Cardiol 6:355-371

10. Nagy KK, Krosner SM, Roberts RR, Joseph KT, Smith RF, Barrett J (2001) Determining which patients require evaluation for blunt cardiac injury following blunt chest trauma. World J Surg $25: 108-111$

11. Sybrandy KC, Cramer MJ, Burgersdijk C (2003) Diagnosing cardiac contusion. Old wisdom and new insights. Heart 89:485489

12. Tenzer ML (1989) The spectrum of myocardial contusion: a review. J Trauma 25:620-627 